\title{
VERGOEDING DER VERLIEZEN DOOR DE VEEZIEKTE VEROORZAAKT.
}

Bij de vele verzoeken en wenschen, bij gelegenheid der veeziekte tot de regeering gericht, heeft zich een nieuwe wensch gevormd. In een tweetal adressen reeds is er op aangedrongen, dat uit 's Rijks kas de verliezen vergoed worden, door de veehouders ten gevolge der veeziekte geleden.

Het eerste adres is door den Gemeenteraad van Voorschoten aan den Koning gericht en luidt als volgt:

"Geeft met verschuldigden eerbied te kennen de Raad der Gemeente Voor"schoten, provineie Zuid-Holland,

"dat ook in zijne Gemeente de Runderpest, zich sedert een gervimen tijd hoeft ", vertoond, en verscheidene veehouders daardoor belangrijke verliezen geleden ,ghebben en gedeeltelijk van weIraart in armoede gedompeld zijn;

„Dat de ziekte zich elken dag dreigt uit te breiden, en de hoofdtak van bestaan "in de Gemeente, reehonderij, in haar hartader aan te tasten.

„Dat de adressant de $\nabla r i j h e i d$ neemt $U$. M. in het belang zijuer gemeente te „, verzoeken, zoo spoedig mogelijk aan de Staten-Generual een wetavoorstel te doen, "waarbij bepaald moge worden, dat an hem, die door de ziekte runderen rerliest, seene matige schadevergoeding vit 's rijks kas zal gegeren worden; en dat de daar,door outstaande uitgaven weder aan die kas vergoed moeten worden, door eene „yblasting te heffen, hetzij op de runderen alleen, hetzij voor éćn zeker deel op "de runderen, voor één ander door het heffen van opcenten op de grondbelasting "Wat de ongebouwde eigendommen betreft, en voor nog één deel dour opcenten yop de personeele of op andere daarvoor geschikte, door het algemeen gedragen "wordende belastingen en dat die belastingen zoolang geheven moeten worden, "totdat het geheele kapitaal, dat door het rijk te dezer zake wordt uitgegeven, "des noods met de rente, weder aan 's rijks kas zal zijn teruggegeven.

"Tot ondersteuning ran zijn rerzoek zij het den adressant vergund met de meeste „yescheidenheid het navolgende ouder de aandacht van U. M. te brengen.

"Een bezwaar dat er tegen kan worden aangevoerd is welligt dat de Stant zich "niet kan bemoeijen met de schade van enkele-burgers, en evenmin als hij versgoedt die, welke brand of watersnood reroorzakt, hij evenmin, hetzij geheel, „hetzij gedeeltelijk kan vergoeden die, welke door de veepest bij den reehouder noutslaat.

Beon, 1806 . 
"Tegen dit bezwar dat wij niet willen verwerpen, veroorloven wij ons op te "trerken, dat de beide eerstgevoemde rampen, hoe vityebreid zij ook mogen zijn, „nltiji blijven beperkt tot zekere plaatsen en tijden; en nimmer volksrampen zijn "op zoo uitgebreide schaal voor zoo langen tijd als de reepest dreigt te worden.

"De Staat geeft hulp daar waar golfslag de dijken teistert, als het betrokken „waterschap de krachten mist om de schade te herstellen. Hij doet dat in het al„gemeen belang, om dat deel van het Vaderland voor ondergang te bewaren.

„De Staat geeft hulp voor de nitvoering van groote werken, waarvoor de pap„ticuliere krachten te kort schiofeo, hij doet dat om algemeene welvanrt te per„meerderen, welke zonder die hulp niet zou kunnen ontstaan.

"Wij bidden U. M. uit dit oogpunt ons rerzoek te beschouwen.

„Een veefouds door particulieren opgerigt kan niet op algemeene deelneming "hopen, omdat de ondervinding van rele vroegere fondsen dasr is, om te bewijzen "Hat zij bij veelvaldige verliezen niet kunnen blijven bestann. Maar bovendien "mogen wij vragen, wie zal een maatschappij oprigten, en zijn kap̧itaal er aan "wagen als hij weet, ten minste de hooge waarschijnlijkheid er voor is, dat hij „binnen weinig tijd voor duizenden on tien duizenden van de door hem te vernwaarborgen voorwerpen vergoeding zal moeten geven.

"Niet alzoo de Staat, die kan verpligten tot terugbetaling van het roorschot dat ,hij doet tot leniging van de nationale ramp, tot zooveel mogelijke bewaring van :gationale welvaart. Hij is in staat die terugbetaling over vele jaren te doen loopen. "Hij handelt uit het oogpunt van zeifbehond, daar hij roorkomt algemeene groote "vermindering van welvoart.

„Er is toch geen tak van volksbestaan die niet in meerdere of mindere mate de ngevolgen van de veepest of reeds ondervindt of in de toekomst, bij algemeene „verarming van de veehouders, ondervinden zal.

„Het stelsel vad schadevergoeding zal krachtig ansporen tot nakoming van de "verordeningen, die tot beteugeling van de ramp gegeven worden; bij niet na„koming kan verbeurte van vergoeding bepaald worden. 'Tot zorgeloosheid zal het „nimmer voeren. Al vergoedt men ook de geheele waarie van het gestorven dier, "in gezonden staat, men vergoedt toch niet, de inkomsten die door middel van het „dier genoten worden, en ieder vechonder weet bu reeds dat het herstelde dier "eene verhoogde waarde heeft, eene raarde die voor hem wel alleen eene ha]ans"waarde is, daar hij met het oog op zijn bestaanmiddel het dier niet in den handel "kan brengea, maar eeve wasrde die hem (gesteld hij had het roornemen er toe) "ran zorgeloosheid zal weerhouden.

„Het belang niet slechts van onze Gemeente, maar van het geheele vader"land doet ons wenschen, dat deze gronden, die wij met den meesten eerbied $n^{\text {aan }}$ U. M. ter overweging anbieden, strekken moge om ons verzoek te doen "verhooren.

't Welk doende, enz."

Het adres. als resultaat der meeting in het Paleis voor Volksvlijt te Amsterdam gehouden, aan den Koning ingediend, luidt aldus :

"Geven enz.

ndat op den 13 Februari 11 . in het Paleis voor Volkswlijt eene vergadering werd "grhoute"u, mar autriding der heersehende vecziekte; 
"dat dezc rergadering dool vele belanghebbenden (vechouders, grondeigenaars, ;,enz.) en deskundigen uit slle corsien des lands werd bijgewoond;

"dat, ofschoon men ter vergadering was opgekomen in de verwachting ran "Ireurige berigten te znllen veroemen, het nict is te ontreinzen, dat de mede"leelingen ran onggetnigen en deskundigen uit. alle onrden eone veel grootere „vrees voor de toekomst voor ouzen geheelen reestapel deden ontstaan:

"dat die tockomst zich te duisterder voordoet, omdat met de vernietiging van „onzen rijken veeslapel, behalve de veehouder ook de landeigenaar, handelaar, „fabriekant, ja bijna alle door dezen slag zouden worden getroffen;

"dat, na de verklaringen der anserige deskundigen, de volgende matregelen "noodzakelijk zija geacht;

„5். De vergoeding (naar de volle waarde in den gezonden staat) uit te strekken „tot al het door de ziekte tc verliezen vee, mits het vooraf is angegeven, en "het daartoe benoodigde kapitaal te vinden hetzij door eene belasting op het vee ..(hoorngeld), hetzij door het waarborgen der rente van aflossing aan de maat"schappij of maatschappijen, die de voorschotten doen.

,'t Welk doende, enz."

Het vooropgesteld beginsel, vergoeding der verliezen door de veehouders geleden, uit de staatskas, verdient met een enkel woord besproken te worden. $O p$ den voorgroud wensch ik te stellen, dat het een bepaalde afwijking is ran het stelsel der staathuishoudkunde, hetwelk tusschenkomst der overheid in de bijzondere aangelegenheden der ingezetenen verbiedt, en als zoodanig, vooral in dit tijdschrift, niet anders dan in afkeurenden zin kan besproken worden. Maar toch bestaat er reden om deze afkeuring met eenige nitroerigheid toe te lichten.

In de eerste plaats is het altijd noodig, - wanneer eenmaal de betrekkingen tusschen volks en regeering, zoo als hier te lande, steunen op de erkende warheden der economiesche wetenschap, zoo vaak een enkel dezer grondwaarheden wordt bestreden of ontkend, voor haar te strijden, even als of de groote overwinning die tot hare meer algemeene erkenuing leidde, nog niet behaald ware.

Te meer bestaat thans de plicht om het in deze adressen vervat verzoek uitdrukkelijk aan de wetenschap te toetsen, nu vooreerst tot aandrang gebezigd wordt het gevaarlijk sophisme: aux grands maux il fuut de grands remèdes, en in de tweede plaats het verzoek uitgaat van eene vergadering, aan wier uitspraken en beraadslagingen, - zoo als in de $\mathrm{T}_{\text {weede Kamer gebleken is, - door }}$ sommigen veel gewicht wordt gehecht. $\left(^{*}\right)$

(*) Op de Ansterdamsche meeting werden wel meer denkbeelden verkondigd, die deu toets eener nadere beschouwing niet doorstaan kunnen. Zoo gprak een 
Tweeledig als het verzoek in de adressen is, komt het mij ook uit twee oogpunten verkeerd voor. In de eerste plaats, omdat het uitgaat van de stelling, dat de Staat de verliezen der veehouders behoort te vergoeden. In de tweede plaats om de wijze ran remboursement, die het aan den Staat aan de hand doet.

I. Mijn tegenwerping tegen de eerste stelling van de verzoekers is, in de meest algemeene termen: de staat behoort geen verliezen van particulieren te vergoeden. Ze berust op eene eenvoudige beschouwing van wat de Staat eigenlijk is. De Staatskas is geen reserve fonds voor de ingezetenen des lands, waaruit de een of ander putten kan, wanneer het hem in zijne nijverheid niet voorspoedig gaat, of wanneer hij zware verliezen lijdt; maar de Staatskas is ons aller kas, gevormd uit ons aller bijdragen, om de staatsdienst geregeld te doen voortgaan, om te zorgen voor de verdediging onzer haardsteden, voor de behartiging onzer belangen buitenslands, voor onze rechtsbedeeling en voor de veiligheid van onze personen en goederen. De Staat is geen op zich zelf staand, buiten, boven of tegenover de maatschappij geplaatst persoon, maar de Staat zijn wij allen te zamen genomen. Het kan dus nooit een wettelijke verplichting voor ons allen worden hem of hen bij to staan, die eenige verliezen geleden hebben, evenmin als wij bevoegd zijn te bepalen, dat de winsten van anderen gelijkelijk of naar eenigen maatstaf door allen zullen gedeeld worden.

Deze regel laat geen uitzondering toe. Hoe exceptioneel de toestanden ook schijnen, als Staat behooren wij allen ons nooit to bemoeien met de toestanden of omstandigheden van eenigen onder ons, tenzij die bemoeiing te brengen zij tot den engen werkkring van den Staat als zoodanig.

Wijkt men van dezen regel af, zoo volgt storing van de natuurlijke orde der maatschappij, het gemeen belang loopt gevaar en lijdt schade in plaats van gebaat te zijn.

De redeneering der adressen volgende, zullen we dit bewaar. heid zien.

der aanwezigen tegen het leggen van „nienwe belasting op het ree, dewijl de peehouder reeds genoeg wordt gedrukt, die door de belasting op het geslacht 20 pCt. betaalt. Dat accijnenen drukken op den consument wordt toch, dunkt mij, Prij algemeen erkend.

Het is te hopen, dat het Verglag der meeting in het Algcmeen Handelsblad, de bron waaruit ik patte, vrij onvolledig als het over het algemeen is, op dit punt het gesprokene nict geheel juist wedergegeren hebbe. 
Het Voorschotensche adres zegt: bij brand en watersnood geeft de Staat geen vergoeding, omdat die altijd beperkt blijven tot zekere plaatsen en tijden, maar bij volksrampen op zoo uitgebreide schaal voor zoo langen tijd als de veepest dreigt te worden, behoort vergoeding gegeven te worden in het algemeen belang, op denzelfden grond, waarop de Staat subsidie verleent in het onderhoud van dijken aan onvermogende waterschappen, of aan de uitvoering van groote werken, waarvoor de particuliere krachten te kort schieten.

Het Amsterdamsche adres deelt mede, dat "groote vrees voor de toekomst van onzen geheelen veestapel" tot het verzoek aanleiding geeft.

Men vreest dus, dat de veeziekte een nationale ramp zal worden door vernietiging (lees: beduidende vermindering) van den veestapel.

Men wenseht deze nationale ramp te keeren door aan het publiek hooger belasting op te leggen, ten einde daaruit de veehouders voor hunne geleden verliezen schadeloos te stellen.

Het middel zal niet alleen tegen de kwaal niet baten, maar integendeel de kwaal verergeren.

Op welken grond toch zal men de reetyphus, - in de onderstelling altijd dat hij blijft doorgaan voor langen tijd, - eene nationale ramp noemen? Niet omdat de veehouders $50 \mathrm{pCt}$. van hun vee aan de ziekte verliezen, niet omdat "verschillende veehouders daardoor belangrijke verliezen geleden hebben en gedeeltelijk van welvaart in armoede gedompeld zijn." Dit zijn de dadelijke gevolgen van de ziekte, die inderdaad door schadevergoeding kunnen hersteld worden. Maar de middelijke gevolgen, die inderdaad van de ramp eene nationale ramp maken, zijn de zoodanige, die door het geheele publiek, niet-veehouders zoowel als veehouders, gevoeld zallen worden. Vooreerst het buiten werk raken van vele arbeiders, in wier onderhoud particuliere en publieke armenkassen moeten voorzien, daarna de daling der prijzen van voor weiland geschikte gronden en der pachten, waarvan de landeigenaars het slachtoffer worden, - het minder aaubod der grondstoffen voor vele takken van nijverheid, looierijen, schoenmakerijen enz., de duurte eindelijk van het vee on de veeproducten, vleesch, melk, boter, kaas enz., tot de meest onontbeerlijke levensbehoeften van het publiek behoorende, en welke door geen enkelen regerings-maatregel,kran worden gekeerd, welke zonder onderscheid ten laste van ieder individu, die tot de natie behoort, zal strekken.

De groote harmonie, die in de maatschappij heerscht, waar men 
niet als in een keurslijf de vrije werking van alle deelen belemmert, en de verliezen van een enkelen stand gedeeltelijk over allen verdeelt, even als ze zorgt dat ook, in tijden van voorspoed, de winsten gedeeltelijk ten bate van allen komen, zal ook in de zaak der veeziekte, als in alle andere werkzaam zijn. Juist de omstandigheid, dat door de vermindering van den veestapel en de daarop volgende duurte van veeproducten, alle ingezetenen min of meer schade lijden, maakt van de veeziekte eene nationale ramp. En hoe wil men deze ramp afweeren of voor den een of ander minder drukkend maken?

De natuurlijke gang der dingen, - onvermogend even als eenige regeering het feit der ziekte zelve weg te nemen, - geeft echter de meest natuurlijke, en juist daarom meest billijke, verdeeling der verliezen over het algemeen aan. De veehouder, eerste verliezer, , erlangt door hem later eenige vergoeding. Immers, tegenover zijn kapitaal-verlies aan gestorven runderen staat de kapitaal-winst aan meerdere waarde der herstelden en overblijvenden, - tegenover zijn rente-verlies aan gemis der producten van de gestorvenen staat de rente-winst an hoogere prijzen, welke hij voor de producten der overblijvenden bedingt. In den eersten tijd dus is de veehouder alleen verliezer, doch het tijdperk der compensatie breekt spoedig aan, en nu is hij de eenige, wiens inkomsten door prijsverhooging vermeerderen. $\left({ }^{*}\right)$

Wat stelt men nu hiervoor in de plaats, wanneer men den veehouder uit de algemeene kas zijne verliezen vergoedt?

ln den grond veranderen kan men de zaak niet: de veeziekte weguemen kan men niet: schaarste van runderen en schaarste van producten blijft dus, ook na de vergoeding, bestain. De wet van prijsbepaling door vraag en aanbod is van regeeringsmaatregelen onafhankelijk.

De veeziekte zal dus blijven een ramp, welker nadeelige gevolgen, op de omschreven wijze, de geheele natie ondervinden zal.

Maar bovendien ontvangt nu de veehouder, volgens den wensch der adressanten, behalve de natuurlijke compensatie, de prijsverhooging, een kapitaal, dat hem althans het kapitaal-vorlies der gestorven runderen vergoedt. Van de andere zijde zal de natie, het groote publiek, behalve de nadeelige gevolgen der prijsverhooging,

(") Deze "Vermeerdering van inkomsten" is natuurlijk op te nemen in vergelijking met het lage standpunt waarop die inkomsten door het veererlies waren gedaald.

RED. 
ook nog in eens, uit de algemeene kas, aan de veehouders eene kapitale som betalen als schadevergoeding.

Vergoeding, uit de Staatskas, van de verliezen door de veehouders ten gevolge der veeziekte geleden, komt dus eenvoudig neer op:

10. het verdubbelen van de nationale ramp.

$2^{\circ}$. het schenken eener premie aan de veehouders.

Eene premie, ziedaar wat het inderdaad wezen zal. Zoo als ik aantoonde, zal, - mengt de Staat zich er niet in, - de veehouder rentewiust genieten tegenover het renteverlies, kapitaalwinst tegenover kapitaalverlies. Maar wanneer vergoeding gegeven wordt, zoo houdt het kapitaalverlies geheel op, daar de volle waarde van het vee in gezonden staat zou vergoed worden $\left(^{*}\right)$. Hot renteverlies wordt mede beduidend gereduceerd, daar het wegens vergoedirg ontvangen kapitaal, hoe ook uitgezet, immer renten afwerpt. Het lrapitaal van den veehouder gaat dus vooruit door de ontvangen som en door de waardeverhooging zijner overige runderen; zijne inkomsten vermeerderen door de prijsverhooging der producten.

Hij geniet dus eene premie uit de kas van het algemeen, dat weldra, de producten van den veestapel koopende, nog eens aan zijue verliezen te gemoet komt.

Kan men eene handelwijze die tot zoodanige resultaten leidt, aanprijzen in het algemeen belang ? Of zal, om met het Amsterdamsche adres te spreken, "landeigenaar, handelaar, fabriekant, ja bijna iedereen" door dezen slag niet meer worden getroffen, dan zoo men de zaak haar natuurlijken gang liet gaan?

II. De wijze, waarop men den Staat aan de hand geeft zich te rembourseeren, bevestigt het verkeerde van den grondslag van het verzoek. Het Amsterdamsch adres verlangt een hoorngeld. Hoe men echter in een adres, dat "vernietiging" van den veestapel voorspiegelt, de verliezen van de veehouders door de veehouders wil doen dragen, is niet duidelijk. Maar ik wil niet aan woorden hangen, en voor "vernietiging" „beduidende vermindering" lezen.

(*) Althans zoo verlangen 't de beide aangehaalde adressen. Andere rekestranteu ziju zoo discreet nict. Zoo deelde dezer dagen de dagbladen een verzoekschrift aan den Koniug mede, - zoo ik mij yiet bedrieg uit Utrecht, - waarin niet alleen vergoeding gevraagd werd van do volle waarde in gezonden toestand pan het vee, maar van een surplus, evenredig aan de winstderving.

Op zoodanige wijze zou inderdaad de ramp een zegen kunven worden... vour den veehouder, maar niet voor het groote publiek! 
Van een hoorngeld van den vernietigden veestapel zal het Rijk niet veel kapitaal ontrangen. Dan, ook in de bedoeling van het adres, zal de invoering van een hoorngeld wel noodig zijn om de veehouders de verliezen der reehouders, dus hunne eigene verliezen, te doen dragen? Zal, bij onthouding der regeering, ook dit resultaat niet langs den natuurlijken weg verkregen worden?

De stellers van het Voorschotensche adres zagen verder. Zij stellen een alternatief òf hoorngeld, òf 'eene drieledige belasting: hoorngeld, opcenten op de grondbelasting der ongebouwde eigendommen, opcenten op 's Rijks personeele, of eenige andere algemeene belasting. Zij stellen voor de verliezen te doen dragen in de volgende orde: veehouders, grondeigenaars, het groote publiek.

of de regeering het recht heeft zoodanige rerdeeling van verliezen te bepalen is zeer betwijfelbaar. Ik voor mij zou oordeelen, dat de regeering, wanneer ze zegt: "omdat de veehouders veel koeien aan de veeziekte verloren hebben, zult gij veehouder, die tien of twintig koeien over hebt, voor ieder een of twee guldens betalen; gij, grondeigenaar, zult voor ieder bunder lands eenige guldens betalen; en gij allen, wie ik op eenige wijze door mijne directe belastingheffing bereiken kan, zult naar den een of anderen maatstaf, de een meer, de ander minder, maar allen iets, opofferen," zich niet op recht, noch op redelijkheid beroepen kan.

Juist de opmerking in het Voorschotensche adres, dat tot deelneming in een particulier veefonds niet kan worden verplichl, brengt ons hier op het juiste terrein.

We zagen reeds, dat het vergoeden van verliezen het nationale van de ramp niet wegnemen kan, omdat ze immer op de geheele natie blijft drukken. Al wordt de vergoeding nóg zoo hoog gesteld, zoo blijft het feit, vermindering van den veestapel, toch dáár, en het geldt nu alleen de vraag, wie de nadeelen dier vermindering dragen zal. We zagen ook, dat als laatste, doch onvermijdelijke verliezer altijd verschijnt het publiek, het groote publiek. Hierin brengt das de schadevergoeding uit de staatskas geen verandering. Ze kan dus nooit zijn een zaak door staatsbelang gewettigd.

Het is dus een ander gevoel, dat op de schadevergoeding aandringt, een gevoel van medelijden of wel de rerwachting, dat bij soortgelijke verliezen in eigen kring op dezelfde wijze ook van anderen schadevergoeding zal ontvangen worden. En nu ontken ik het recht van den Staat mij te verplichten medelijden te betoonen aan wien ook, of mij de verplichting tot bijstand op te leggen jegens een 
ander, zelfs met het uitzicht van bij eigene verliezen op dezelfde wijze geholpen te worden.

Dit uitzicht echter kan niot dan zeer onzeker zijn. Naar het beginsel van het Voorschotensche adres zal de effectenhouder en fabriekant aan de verliezen van den veehouder, door directe geldoffers betalen; - maar zal men dan ook de zekerheid geven kunnen, dat de een uit de staatskas vergoeding ontvangen zal, wanneer hij door eenig staatsbankroet te gronde gericht wordt, of dat de ander uit de Staatskas zal worden schadeloos gesteld, indien ten gevolge van oorlog of concurrentie, zijne débouchés gesloten zijn of zijn debiet vermindert? En dit zal toch in foro conscientiae het geval behooren te zijn, wil men niet onbillijk worden.

Het Voorschotensche adres, - meer betooogend dan het Amsterdamsche, - verwerpt de vergelijking met brandschade. Deze is, zegt het, meestal van localen aard. Il geloof niet, dat de vergelijking juist daarin hapert. Naar mijne meening schuilt het onderscheid vooral hier, dat men meestal verstandig genoeg is zich tegen brandgevaar te verzekeren. Bestonden er geen brandassurantiemaatschappijen, zoo zou schadeloosstelling wegens brand even billijk zijn als die wegens veezielkte. Bestond er, van den anderen kant, een vee-verzekeringfonds, het Voorschotensehe adres zou vermoedelijk niet zijn opgezonden.

Het lokaal karakter eener zaak komt alleen te pas, waar men in het publiek belang spreekt. Doch waar alleen medelijden, alleen de prijzenswaardige aandrift om de verliezen zijner naasten te vergoeden tot handelen aanzet, komt de uitgebreidheid van de ramp niet in aanmerking, en heeft de man, wiens huis is afgebrand zonder verzekerd te zijn, evenveel aanspraak op tegemoetkoming als alle veehouders, wier stallen door den rundertyphus geledigd zijn.

Tegen de willekeurige bepaling der orde, waarin de verliezen zullen geleden worden in het latere remboursement van den staat heb ik ook bezwaar. Door billijk te willen zijn vervalt men tot onbillijkheid. Van het hoorngeld sprak ik reeds. Doch zullen de grondeigenaars nog niet genoeg benadeeld worden door de verlaging der landprijzen en pachten en door de prijsverhooging der producten, dan dat men hen nu nog eens laat betalen, door meer opcenten op de grondbelasting en op het personeel te heffen? Bovendien, wat moet er worden van die groote klasse onzer landbouwers, de bezwaarde kleine eigenaars? Zij zullen vooreerst worden gedrukt door het hoorngeld, daarna door de opcenten op de grondbelasting, om eindelijk met het gansche publiek nog eens de ver- 
hoogde personeele belasting te betalen. Fn toch is één enkel der natuurlijke gevolgen van de veezielte, - de vermindering der landprijzen, - reeds voldoende om hunne toestand uiterst hachelijk te doen zijn.

Een billijke maatstaf, om daarnaar ieder te verplichten in de verliezen der veehouders te deelen, zal hoogst waarschijnlijk niet te vinden zijn. Evenmin als de adressanten uit Amsterdam, evenmin als de gemeenteraad van Voorschoten, weet ik er een aan te wijzen, die niet vele bezwaren met zich voert, zelfs al kwame dat groote bezwaar, onbillijkheid van den geheelen maatregel, er niet bij.

Het eenig middel, dat ik er op weet, is: laissez faire, laissez passer. Gij, regeering, onthoudt u tusschen beiden te komen tot vergoeding der geleden verliezen. Gij, publiek, laat u niet te spoedig door medelijden vervoeren, want de arme veehouders zullen op den duur niet de lijdende partij blijven. Wanneer gij gaarne iets tot hunne tegemoetkoming mocht willen afzonderen, bewaar het nog een poos, en het zal dra versmelten in de prijsverhooging van boter, kaas, melk, vleesch, en wat dies meer zij.

Al geeft gij, - of de staat, dat zijt gij en ik, - de ruimste vergoeding aan den veehouder, al brengt gij de grootste offers, gij kunt de natuur niet dwingen; gij kunt de doode koeien niet weer levend maken; gij kunt de prijsverhooging van het vee niet keeren; gij kunt de prijzen uwer dagelijksche behoefte voor zoover die van den veestapel afkomstig zijn, niet kunstmatig voor stijging bewaren.

Een ding kunt gij echter wèl doen, dat is - zorgen, dat ge, in plaats van éénmaal, tweemaal betaalt: ééns vrijwillig, de tweede maal door de omstandigheden gedwongen.

Maar eilieve, dan die vrijgevigheid ook overgelaten aan den vrijen wil van de welgezinden onder ons. Moet er een offer van Christelijke liefde gebracht worden, laat ons dan de waarde van dat offer niet verminderen door er elkander toe te dwingen.

Hillegersberg, Maart 1866. Mr. A. M. Mass Geestreranos. 